\title{
SUBSÍDIOS PARA ESTUDOS SOBRE TRANSCRIAÇÃO DE POESIA EM AMBIENTES DIGITAIS
}

\author{
Giuliano Tosin \\ Faculdades Atibaia \\ giulianotosin@gmail.com
}

\begin{abstract}
Resumo: O texto concentra-se no estudo da reinvenção, através da poética da transcriação, de poemas em ambientes digitais, entre eles a internet. Aborda fundamentos teóricos pertinentes a esta atividade em diferentes vertentes (tradução intersemiótica, estudos comparativos e estudos interartes, entre outros) e, a partir destes, propõe uma reflexão metodológica sobre o assunto.
\end{abstract}

Palavras-chave: poesia digital; poesia eletrônica; tradução intersemiótica; transcriação; intermidialidade.

\section{Traduzir com os meios do seu tempo}

O objeto deste estudo é a tradução de poesia através de diferentes mídias, assunto que pertence ao campo da tradução entre meios, intermidiática, ou intersemiótica. Trata-se de um universo de produção muito amplo, a começar pela variedade de definições que podem ser atribuídos ao termo "mídia", na imensidão dos meios de comunicação humana. Depois, pela infinidade de traduções realizadas entre diferentes meios, se considerarmos que, cada vez que uma pessoa lê em voz alta um poema escrito, por exemplo, está recriando esse poema em outro meio diferente do original, e usando para isso sua expressividade e criatividade individual na leitura. Para tornar viável a realização deste estudo, iremos delimitar nosso foco nas traduções de poesia que envolvem mídias eletrônicas e digitais, que são as que melhor caracterizam o tempo presente.

Para Arlindo Machado, essas mídias estão permanentemente ao redor dos artistas na atualidade, "despejando o seu fluxo contínuo de sedução audiovisual, convidando ao gozo do consumo universal e chamando para si o

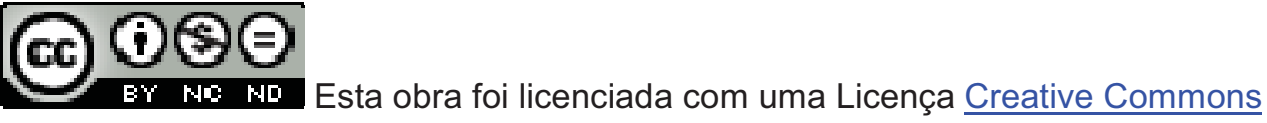

Texto Digital, Florianópolis, v. 7, n. 2, jul./dez. 2011. ISSNe: 1807-9288 
peso das decisões no plano político". Sendo assim, continua o autor, "é difícil imaginar que um artista sintonizado com o seu tempo não se sinta forçado a se posicionar com relação a isso tudo e a se perguntar que papel significante a arte pode ainda desempenhar nesse contexto". As respostas, segundo Machado, representam a diferença introduzida pelo artista no universo midiático: ao invés de alimentar a "máquina produtiva" com enunciados de consumo, ele pode apresentar um projeto crítico relacionado aos meios e circuitos com os quais opera. Sendo assim, interfere na lógica das máquinas e dos processos tecnológicos, subvertendo e desnudando suas funções prometidas, e "desprogramando" a técnica (2007, p. 22).

Escrever para o seu tempo significa para os poetas e tradutores contemporâneos, ao menos parcialmente, o uso das mídias eletrônicas. Lauro Amorim observa que os trabalhos dos tradutores sempre "estão inscritos em um momento histórico caracterizado por certos cânones que direcionam os 'caminhos' que podem ou não ser tomados em uma tradução" (2005, p. 59). O grande interesse pelas mídias eletrônicas nos universos artístico e acadêmico nos últimos tempos nos faz pensar que, no mínimo, estamos passando por um "processo de canonização" das mesmas e do seu uso nas formas de representação estética, e isso se reflete, sem dúvida, na poesia.

A possibilidade de incorporar à poesia as características de diferentes mídias tem motivado iniciativas que vão desde a espacialização de Un Coup de Dés aos poemas virtuais interativos disponíveis na internet, cada qual inspirado nas inovações técnicas de sua época. Antonio Risério (1998, p. 49) cita uma ideia contida em Literatura e Revolução, livro de Leon Trotski publicado originalmente em 1923, que define de modo simples e preciso a relação entre as transformações históricas do mundo e as alterações que estas motivaram na poesia. Para Trotski, é ingenuidade supor que a poesia pudesse vir de Homero a Maiakovski sem que a luz elétrica não tivesse nada a ver com isto. Segundo Risério, a postura do poeta diante do mundo urbano-industrial deve ser analisada em, pelo menos, dois planos. Um deles é o plano de sua atitude ideológica diante da sociedade, que pode ir da "aceitação celebratória" ao "extremo da recusa nostálgica". O outro é o plano de sua disposição em 
relação aos meios de comunicação e às técnicas de criação presentes nesta sociedade, onde o poeta, como inventor da palavra, utiliza e explora as técnicas de criação, passando através delas sua condição ideológica e sensível (Op. cit., p. 47).

Philadelpho Menezes observou que o diálogo entre a poesia visual e as novas tecnologias manteve-se, durante muito tempo, vinculado às velhas fórmulas, importadas dos poemas estáticos e bidimensionais. Segundo ele, o importante no uso da tecnologia pelos poetas "é ver o que ela possui e não oferece, o que ela tem de programado que pode ser desprogramado pelo uso estético, ao contrário do uso utilitário ou previsto". E segue: "é como se, nas mãos do artista, uma tecnologia de ponta se transformasse num artesanato de si própria, graças a um uso humano, que nega sua sofisticação pretensamente futurista" (1998, p. 117).

As possibilidades de operar um signo virtual num meio informático são um grande atrativo para vários poetas na atualidade. A simulação luminosa do computador dá ao poema uma materialidade flexível, que convida à manipulação, ao ir e voltar, ao corrigir e alterar novamente. Risério (1998, p.128-130) destaca que, com o computador, o poeta pode fazer com que a escrita "dê saltos nijinskianos" e "passinhos chaplinianos", pois, com um simples toque numa tecla, a configuração gráfica de uma obra pode mudar completamente. Do mesmo modo, o som de um poema gravado digitalmente pode receber tratamentos que alterem suas características por completo, abrindo um feixe quase infinito de possibilidades criativas.

Todavia, cabe lembrar que a promoção de diálogos entre conteúdos verbais e outras formas de iconicidade, como a visual e a sonora, são recorrentes na história da poesia, sobretudo se levarmos em conta a produção dos poetas dos movimentos de vanguarda, do futurismo ao letrismo e à poesia concreta, entre outros. A tradução de poemas para mídias eletrônicas trouxe consigo a acentuação daquilo que já era inerente aos poemas visuais, concretos, sonoros, entre outros: a exploração do cruzamento entre os sentidos do leitor, através de dispositivos sinestésicos presentes nas obras que, normalmente, 
dialogam com sua porção verbal. Uma tradução desse tipo gera diferentes percursos sensoriais, criando intercâmbios entre os sentidos do corpo, através do emprego de meios técnicos variados.

Com o objetivo de situar o leitor no universo da tradução de poesia através das mídias no Brasil, apresentaremos a seguir uma breve recapitulação da produção nacional mais representativa desse tipo. Essa apresentação será feita sem grandes pretensões, visto que a catalogação de obras, eventos e autores passa ao largo dos propósitos deste trabalho. Os casos citados, longe de buscar representar todas as traduções realizadas no Brasil, servem para ilustrar um pouco da grande quantidade de iniciativas unindo poesia, tradução e mídias no país.

Em 1975, o poema Cidade/City/Cité, de Augusto de Campos, recebeu uma primeira tradução "digital" de Erthos Albino de Souza, que o inseriu num cartão de papel perfurado, que era a memória de computador na época. O resultado plástico do cartão escuro sobre um fundo claro simulava as janelas iluminadas dos prédios, na paisagem noturna de uma cidade. O vídeo Non Plus Ultra, realizado em 1985 por Tadeu Jungle, trouxe esse mesmo poema para a tela pela primeira vez. Ele seria traduzido posteriormente de várias formas, desde música à performance e artes plásticas, por Regina Silveira, Rufo Herrera, Gilberto Mendes, entre outros.

No início dos anos 80 , com o começo do uso da holografia para produção de poesia, o poema Rever, de Augusto de Campos, foi reconstruído pelo hológrafo John Webster, em Londres, a partir de um protótipo de Wagner Garcia. Após receber uma versão na forma de uma escultura acrílica feita pelo artista Zé Neto, voltou a ser realizado em holografia por Moiysés Baumstein, que traduziu para este suporte também outros poemas de Augusto de Campos. Rever foi ainda refeito em laser, néon e animação digital.

O poeta que mais traduziu e teve seus poemas traduzidos para outras mídias no país foi o próprio Augusto de Campos. Em 1984, a equipe da produtora Olhar Eletrônico, com a colaboração de Wagner Garcia e Mário Ramiro, 
transformou o seu Pulsar, poema onde as letras imitam corpos celestes num céu noturno, no primeiro videopoema animado por computador produzido no país. O compositor Caetano Veloso havia traduzido, em 1975, o mesmo poema em canção, assim como fez com Dias Dias Dias. Ambas integram a Caixa Preta, conjunto de obras editado por Augusto e Julio Plaza.

O programa Jornal de Vanguarda, veiculado pela TV Bandeirantes em 1988 e 1989, contava com a participação de Paulo Leminski, que apresentava variedades relativas à língua, cultura e poesia. Além de performances poéticas, Leminski também levou para a TV alguns videopoemas, parte deles traduções de poemas impressos de sua autoria, como Metamorfose. Durante os anos 80, Julio Plaza traduziu poemas de Paulo Leminski, Bashô e outros, para videotexto. No início dos anos 90, Augusto de Campos traduziu seu poema Cidade para uma versão animada em seu Macintosh pessoal. ${ }^{1}$ Em 1993 foi a vez de Arnaldo Antunes, em parceria com Célia Catunda, Kiko Mistrorigo e Zaba Moreau, realizar o projeto Nome, um trabalho de vídeo e computação gráfica que contém a tradução de poemas que já haviam sido publicados anteriormente pelo poeta.

Intervenções realizadas na cidade de São Paulo em diferentes ocasiões mostraram quanto os poemas concretos são moldáveis às paisagens e à comunicação urbana, como era previsto no projeto do movimento concretista. O poema Quasar, de Augusto de Campos, foi exposto em um painel luminoso no Vale do Anhangabaú, no centro da cidade (1982). A mostra Skyart, realizada na USP em 1985, apresentou uma projeção do poema Código, também de Augusto e, em 1991, projeções de poesia com uso de raios laser levaram poemas como Rever, Risco e Cidade/City/Cité, todos de Augusto de Campos, às alturas dos arranha-céus na Avenida Paulista. $\mathrm{Na}$ ocasião, também participaram Haroldo de Campos, Arnaldo Antunes e Walter Silveira. Em 1991, o cineasta Julio Bressane dirigiu, a partir do livro Galáxias, de

\footnotetext{
${ }^{1}$ Diversos poemas de Augusto de Campos foram reelaborados digitalmente por ele próprio para integrar o CD-Rom Clip-Poemas, anexo ao livro Não (2003). Alguns deles são: Pérolas para Cummings, O Mesmosom, Rever, Sem-saída, Criptocardiograma e Caracol.
} 
Haroldo de Campos, Galáxia Albina e Galáxia Dark, duas transfilmagens da renomada obra do poeta.

Não poderiam deixar de serem citadas as traduções feitas no projeto "VídeoPoesia", realizado entre 1992 e 1994 no Laboratório de Sistemas Integráveis da Escola Politécnica da Universidade de São Paulo, com a participação de Augusto e Haroldo de Campos, Décio Pignatari, Arnaldo Antunes e Julio Plaza, numa experiência mediada por Ricardo Araújo. Na ocasião, alguns poemas de autoria dos próprios tradutores foram reelaborados através de animação digital, com recursos considerados de ponta para a época. Julio Plaza voltou a traduzir poemas para animação computadorizada em 1996, no Laboratório de Informática do Instituto de Artes da Universidade Estadual de Campinas. O projeto foi uma parceria com Luciana Chagas e proporcionou a tradução de poemas de Augusto de Campos, Paulo Leminski, Alice Ruiz e do próprio Plaza.

O CD e espetáculo performático Poesia é Risco, apresentado em 1995 por Augusto de Campos e Cid Campos, contém interpretações dos poemas Lygia Fingers, Tensão, Cidade/City/Cité, O Quasar, entre outros, da autoria de Augusto de Campos. Em 1998, Philadelpho Menezes e Wilton Azevedo lançaram o Cd-rom Interpoesia, com diversos poemas digitais, entre eles algumas traduções "inter-semióticas" como Máquina, poema visual de Menezes elaborado muitos anos antes. O curta-metragem Hi-Fi, realizado em 1999 por Ivan Cardoso, apresenta versões para poemas de Augusto de Campos como Cidade/City/Cité, Poema-Bomba, Ex-tudo e Rever, além de outros poemas concretos no áudio. Em 2005, Omar Khouri inspirou-se no verso inicial do célebre poema L'azur, de Stephane Mallarmé, para fazer Homenagem a Mallarmé, um poema digital elaborado em parceria com Fábio Oliveira Nunes, que faz parte do Cd-rom Nóisgrande, organizado pelo próprio Nunes. Um poema visual sem título de Torquato Neto foi transformado em animação digital interativa por Audrei Carvalho em 2004, na ocasião do festival FILE, em São Paulo. A tradutora repetiu o procedimento com uma série de poemas de Augusto de Campos, num trabalho que culminou em sua dissertação de mestrado pela PUC-SP (CARVALHO, 2007). 
A internet sedia diversos casos de tradução que conduziram poemas e autores brasileiros para o contexto digital, entre eles animações como Lua na Água, de Paulo Leminski, por Elson Fróes, feita em 1997, os poemas Life e Beba CocaCola, de Décio Pignatari, traduzidos por Kirby Conn em 2001 para o site Imediata/BVP, e a Rã de Bashô, que tem versões nos sites de Haroldo e Augusto de Campos. Fábio Oliveira Nunes recriou, em diferentes ocasiões, poemas visuais de autores nacionais para a rede, como Cresce, de Arnaldo Antunes, Epitalêmio II, de Pedro Xisto, e BR, de Villari Herrmann, entre outros, traduzidos em 2003 para a revista digital/site Artéria 8, produzida por Nunes e Omar Khouri.

Poetas estrangeiros também tiveram suas obras re-visitadas em suportes digitais no Brasil: Khlebnikov foi recriado em 2008 por André Vallias para a revista/site Mnemozine 4. Versos de Baudelaire foram utilizados por Philadelpho Menezes em uma instalação multimídia na II Bienal do MERCOSUL, em 1999, e o poema O Eco e o Icon, do português Ernesto M. de Melo e Castro inspirou uma versão em VRML por Silvia Laurentiz, em 1998.

Um grande projeto intitulado Poesia Concreta: o Projeto Verbivocovisual, realizado em 2007, abrangeu parte da produção do movimento e disponibilizoua na forma de site, CD, DVD e exposição. Neles, são inúmeros os casos de poemas convertidos para mídias eletrônicas e adaptados à natureza de cada suporte. No CD, dirigido por Cid Campos, encontramos poemas que foram musicados ou interpretados vocalmente pelos autores e convidados. No DVD, dirigido por Sérgio Zeigler e Walter Silveira, estão presentes animações computadorizadas produzidas a partir de poemas originais, roteirizadas pelos diretores e realizadas por Rodrigo Fiorenza. Já no site, elaborado por André Vallias, encontramos poemas recriados em áudio e vídeo, além de extenso material iconográfico e textual sobre o movimento. A exposição, exibida em São Paulo e Belo Horizonte sob a curadoria de Cid Campos, João Bandeira, Lenora de Barros e Walter Silveira, apresentou diversos poemas traduzidos para a ocasião. No conjunto total, foram recriados poemas de Augusto e Haroldo de Campos, Décio Pignatari, José Lino Grünewald e Ronaldo Azeredo, além de traduções de outros poetas por eles realizadas. Participaram também 
desse projeto Arnaldo Antunes, Arrigo Barnabé, Boris Schnaiderman, Caetano Veloso, Gilberto Mendes, Lívio Tragtenberg, Lucio Agra, Omar Khouri e Wilson Sukorski, entre outros.

\section{A tradução intersemiótica}

Em seu artigo "Aspectos Linguísticos da Tradução", Roman Jakobson afirma que existem três maneiras de realizar uma tradução: 1) utilizando signos da mesma língua, que ele chama de tradução "intralingual", ou "reformulação"; por exemplo, converter o termo "solteiro" numa designação mais explícita, que é "homem não casado"; 2) utilizando signos de outra língua, que é a tradução "interlingual", ou "tradução" propriamente dita, como a conhecemos; 3) em outro sistema de signos não-verbais, classificada pelo autor como "transmutação", ou tradução "inter-semiótica". Sem aprofundar-se nesse conceito, o autor volta a citá-lo no final do mesmo texto, dessa vez como a tradução "de um sistema de signos para outro, por exemplo, da arte verbal para a música, a dança, o cinema ou a pintura" (JAKOBSON, 1971, p. 64).

Comparando os dois únicos trechos nos quais o autor cita a expressão "tradução inter-semiótica", pode-se observar uma pequena diferença na definição do conceito. Primeiramente, Jakobson refere-se à tradução de conjuntos de signos verbais para não-verbais e, posteriormente, quando dá exemplos desses tipos de conjuntos de signos que seriam considerados nãoverbais, o autor cita a pintura, a música e o cinema. Mas cabe lembrar que estes, por sua vez, podem apresentar fusões com conteúdos verbais, a exemplo dos escritemas ou outras formas de intervenção verbal na pintura cubista, e as canções e óperas no caso da música, ou as falas e legendas no cinema.

Interpretando a definição de Jakobson, portanto, é possível concluir que o autor se referiu à tradução inter-semiótica como um tipo de tradução que transforma um conjunto de signos verbais em outro meio expressivo de natureza diferente, que não seja exclusivamente verbal, ou nem um pouco verbal. $O$ autor lançou um conceito que inicialmente pretendia abranger só casos mais próximos ao 
seu universo, o linguístico, e por isso a conotação verbocêntrica dada ao termo "tradução inter-semiótica". Como definir, no entanto, as operações tradutoras que procuram transferir significados reconstruindo obras em linguagens diferentes, sejam elas verbais ou não? Não seriam todas inter-semióticas?

Uma obra que impulsionou os interesses pela tradução através de diferentes mídias, sobretudo no Brasil, foi o livro Tradução Intersemiótica ${ }^{2}$, de Julio Plaza. Utilizando o conceito de Roman Jakobson e valendo-se, sobretudo, de fundamentos da semiótica de Charles Peirce, Plaza aprofundou-se no assunto, analisando processos desse tipo de tradução desde sua idealização, à realização e suas possíveis interpretações. Propôs também o estudo de casos selecionados de tradução entre mídias, quase todas realizadas por ele próprio, algumas envolvendo poesia. Diante da escassez de princípios teóricos próprios para subsidiar uma teoria da tradução intersemiótica, o autor recorreu a fundamentos de tradução de poesia desenvolvidos, principalmente, por Roman Jakobson, Haroldo de Campos e Octavio Paz, por ele adaptados para pensar a tradução entre diferentes mídias.

Percebemos, portanto, que, para Jakobson, a poesia é intraduzível, sobretudo em virtude dos recursos paronomásticos normalmente empregados, sendo possível somente a "transposição criativa", seja ela intralingual, interlingual ou intersemiótica. Essa visão coincide com o que sempre foi defendido por Haroldo de Campos, que classifica seu extenso trabalho de tradução de poesia como "transcriação". Já para Octavio Paz (apud PLAZA, 1987, p. 39), a tradução é uma operação análoga à criação, mas que se desenvolve no sentido contrário. Na criação, segundo Paz, a matéria-prima é a linguagem em movimento, e o esforço do artista é todo em cristalizá-la numa forma definida, no caso, o poema. Traduzir seria "colocar este cristal de seleções em movimento, para voltar a fixá-lo em um sistema de escolhas outro, análogo ao primeiro".

\footnotetext{
${ }^{2}$ Chama a atenção a diferença de grafia entre a tradução "inter-semiótica" definida por Jakobson e a "intersemiótica" utilizada por Plaza.
}

Texto Digital, Florianópolis, v. 7, n. 2, jul./dez. 2011. ISSNe: 1807-9288 
Criação e tradução são, segundo Plaza, operações onde se produz, "com meios diferentes, efeitos análogos" (1987, p. 26). Fazendo uma síntese das ideias desses autores, e adequando-as às suas noções empíricas decorrentes de experiências práticas com traduções entre diferentes meios, Plaza busca tecer uma teoria específica para a tradução intersemiótica. O autor ressalta duas etapas básicas do processo de tradução: a leitura e a invenção. Na primeira, o tradutor apreende o objeto a ser traduzido, interpreta-o e o sintetiza para, no segundo momento, criar uma nova forma, inspirada na original. A leitura é uma geração indefinida de possibilidades de interpretação, um diálogo entre o repertório do leitor e o conteúdo da obra lida, convocando outros elementos que se agregam ao material lido e fazendo deste percurso um acontecimento único. Qualquer leitor participa ativamente de um processo comunicativo como criador de "versões" daquilo que lê, ocupando assim um papel de re-criador da obra. Como observa Haroldo de Campos, "o receptor não é somente alguém que recebe algo, nem está somente em estado passivo; em termos ótimos, ele deveria ser um co-autor da informação". 30 ato de leitura, portanto, é marcado pela invenção de novas interpretações ou traduções de diferentes formas daquilo que se lê, agregando à obra lida os traços da subjetividade do leitor.

A síntese obtida com a leitura não é uma interpretação definitiva para o poema, mas uma busca que visa alcançar o que há de essencial nele, sem esquecer as condições contextuais em que o mesmo foi produzido. Depois de alcançada essa síntese, chegará o momento em que será preciso traduzi-la em um meio particular, no qual tomará existência, ostentando a condição de tradução em relação ao original. O momento intermediário à leitura e à concretização material da obra envolve, segundo Plaza, processos de natureza imaginativa e operativa. A primeira está presente predominantemente no desenvolvimento da ideia e mistura a razão com um alto nível de intuição. A segunda é a da realização prática, guiada predominantemente pela racionalidade, aplicada a um meio técnico de realização (1987, p. 37-39).

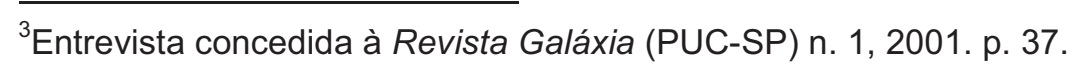

Texto Digital, Florianópolis, v. 7, n. 2, jul./dez. 2011. ISSNe: 1807-9288 
Toda e qualquer invenção começa com um instante de caráter espontâneo que aparece à mente "como epifania, imediatamente desprendida das amarras de um raciocínio lógico", configurada como insight (Ibid., p. 40). Não é fruto de uma sucessão de pensamentos naquele momento, mas um lampejo súbito que incita o intelecto ao ato criador. No caso da tradução, este insight inicial é motivado pela forma da obra original, absorvida a partir do processo de leitura, uma leitura atenta, destinada a solucionar o problema de como conduzir a tradução. Segundo Julio Plaza e Monica Tavares, a invenção não se dá de modo contínuo, mas "renova-se sempre e admite feedbacks alimentados pela atividade experimentadora e pelas ideias criadoras" (1998, p. 72).

No momento da invenção com mídias eletrônicas, a sinergia entre o homem e a máquina se manifesta através do diálogo estabelecido entre a subjetividade do criador e as possibilidades de realização com o meio escolhido. Esse diálogo apresenta diferentes possibilidades (ou poéticas), que Plaza e Tavares classificam em: poética por associação, que é aquela que utiliza repertórios armazenados em memórias eletrônicas; poética do acaso, criada a partir de processos aleatórios; poética dos limites, que trabalha com um repertório delimitado onde prevalece a ideia minimalista de fazer "mais com menos"; poética de projeto, fortemente regida pela racionalidade programadora; poética da simulação, onde a imagem é construída através de modelos de síntese que simulam a realidade, e as poéticas experimentais, onde a concepção vai surgindo a partir da própria realização (1998, p. 124-194). Os meios eletrônicos, como forma de expressão em incessante renovação, apresentam ao artista capacidades inéditas de cognição (sensíveis e inteligíveis), trazendo possibilidades que exigem dele uma "familiarização com os modelos tecnocientíficos em uma interligação de práticas e saberes disposta em relações interdisciplinares" (p. 64).

Julio Plaza apresenta uma classificação que divide as traduções entre diferentes mídias em transposições, transcodificações e transcriações. ${ }^{4}$ Essa

\footnotetext{
${ }^{4}$ Essa tipologia é baseada na classificação dos signos em relação aos seus objetos dinâmicos, ou referentes, segundo Charles Peirce: índice, símbolo e ícone. Para Plaza estes originam, respectivamente, a transposição, a transcodificação e a transcriação.
} 
classificação leva em conta quanto uma tradução continua apegada ao original, ou o reinventa, abrindo margem para certa autonomia. Além do resultado, o processo de tradução também é diferente em cada uma delas, dado que seguem diferentes finalidades. Plaza faz questão de destacar que essas categorias não são uma "grade classificatória de tipos estanques que deve funcionar de modo fixo e inflexível", mas sim "uma espécie de mapa orientador para as nuanças diferenciais" das traduções. Deixa claro também que os diferentes tipos podem ocorrer de modo algumas vezes simultâneo em uma mesma tradução e, sendo assim, essa tradução acabaria proporcionando um cruzamento dos tipos, ao ser classificada (1987, p. 89).

Em sua leitura, "transposição" seria o tipo de tradução que estabelece uma relação de contiguidade com seu original, como se a forma da obra original estivesse sendo impressa em um novo meio, metaforicamente. Transpor o conteúdo de um poema para outro meio, nesse caso, seria tentar transportá-lo na íntegra, como ele é, para o novo ambiente de realização. O poema passa a "funcionar" de acordo com as características do novo suporte, mas sem alterações notáveis em sua forma e no modo como ele "funciona". Por exemplo: tomar o texto de um poema, parcialmente ou na íntegra, e fazê-lo "passar" pela tela de um computador, de uma TV, ou outro meio similar (Ibid., p. 91).

Já a "transcodificação" seria a tentativa de recompor a forma da obra original usando outros signos, característicos do meio que está sendo usado, através da criação de um código de correspondência sobre o qual se baseará a tradução. O código inventado pelo tradutor é uma convenção que explica a correspondência entre os elementos parciais que compõem o original e a tradução. Permite ao tradutor a liberdade de criar uma convenção inédita, baseada em elementos de outra linguagem inspirados por aqueles presentes na obra que origina a tradução. Por outro lado, restringe a autonomia do tradutor por exigir que ele combine os novos elementos da mesma maneira que estavam dispostos na obra original. Para cada letra de um poema, por exemplo, um artista plástico que irá traduzi-lo pode imaginar um ícone correspondente, com sua forma, cor, distribuição espacial etc., mas terá de 
usar esse ícone dentro das normas estabelecidas por ele na tradução. É uma maneira de organizar a forma, de modo a criar uma correspondência, como se a obra original fosse reconstruída de outro modo, mas a maneira como os elementos estão dispostos em sua apresentação copiasse a primeira (Ibid., p. 93).

Uma transcodificação realizada pelo próprio Plaza, se tomada como exemplo, talvez possa esclarecer melhor esse tipo de tradução: o artista transformou o poema Nasce/Morre, de Haroldo de Campos, em uma composição visualgeométrica baseada em triângulos, onde cada palavra que compõe o poema foi convertida em um tipo de triângulo: "nasce" foi substituída por um triângulo branco invertido, "morre" por um triângulo branco em posição natural, "desnasce" por triângulo preto invertido, e assim por diante. Em seguida, esses triângulos foram combinados espacialmente do mesmo modo que as palavras no poema original, copiando sua forma.

Por fim, Plaza define como "transcriação" a tradução intersemiótica que se baseia no "princípio de similaridade" com o original, e a forma adotada pela tradução constrói analogias com este, "equivalências entre o igual e o parecido" (1987, p. 89-90). Nesse caso, original e tradução não estão "conectadas" diretamente, mas as características resultantes na tradução fazem lembrar o original, "despertando sensações análogas", produzindo significados "sob a forma de qualidades e de aparências entre ela própria e seu original" (p. 93). Revisitando a linha de pensamento poundiana via Haroldo de Campos, Plaza conclui que "traduzir com invenção pressupõe reinventar a forma" (p. 98).

A definição de transcriação é apoiada nas análises de casos práticos que Plaza apresenta na segunda parte do seu livro Tradução Intersemiótica. Nesse sentido, compreendemos a transcriação como a tradução que se caracteriza pela criação de traços similares àqueles que a obra original apresenta, ou seja, que a imita através de uma nova forma, com características semelhantes à original, fazendo lembrá-la. O resultado é uma tradução que estabelece analogias com a original, sem o comprometimento de tentar sê-la em outro meio. É um procedimento onde o tradutor tem consciência da autonomia que a 
tradução irá adquirir, e de que irá interferir de modo ativo na busca de novos horizontes para a obra. A transcriação absorve as qualidades, aparências e significados propostos pela original e os reconstrói numa estrutura que faz lembrá-la através de referências, sejam estas mais, ou menos, nítidas.

\section{Subsídios para um estudo da transcriação através de diferentes mídias}

Analisar a transcriação de poesia através das mídias é um objetivo que requer o uso de ferramentas teóricas adequadas. A teoria da tradução intersemiótica, que foi abordada no item anterior, é uma delas, e sua aplicação no universo da poesia foi realizada pelo próprio Julio Plaza, conforme vimos. Neste item apresentaremos outras teorias que podem contribuir para a formulação de um percurso que auxilie na compreensão das transcriações de poesia através dos meios. O objetivo é tomar emprestados fundamentos dessas teorias para utilizá-los, sempre que necessário, como instrumentos nas análises de casos práticos. Essas teorias foram selecionadas por sua afinidade com as circunstâncias que cercam as experiências de transcriação de poesia, que se dá através de um ponto principal: todas tratam de relações entre obras artísticas envolvendo sempre mais de uma mídia.

Comecemos pela dissertação Um Poeta de Vanguarda Dialoga com as Artes Visuais: a Transcriação Interpoética de Haroldo de Campos, na qual Rogério Prestes de Prestes aborda um conjunto de textos de Haroldo de Campos relativos às artes visuais, que trata de obras de diversos artistas plásticos e gráficos, envolvendo diferentes técnicas e estilos. Esses textos poderiam ser definidos como críticas de arte, mas Haroldo de Campos, através de seu "personalíssimo método crítico-criativo" utilizado para escrevê-los, fez com que eles incorporassem elementos estruturais das obras a que se referem (Op. cit., p. 9). Esses textos, que trazem em si marcas explícitas do contágio de seu autor com as obras visuais, são definidos por Prestes como "transcriações interpoéticas", e dividem-se em "poemas-críticos" e "prosa metapoética":

Campos tem produzido textos originais e variados quanto a suas estruturas e formas de diálogo com as obras 
motivadoras. Essa diversidade de textos é mais um elemento que impulsiona meu pensamento de que eles estão estruturados semelhantemente às obras que os originaram. (...) os textos de Haroldo de Campos sobre artes visuais são únicos se comparados à crítica de arte convencional. Por questões operacionais da pesquisa, sobretudo didáticas, separei os textos escolhidos em grupos distintos: PoemasCríticos; Prosa Metapoética; e Críticas Propriamente Ditas. É claro que me detive nos dois primeiros grupos, uma vez que a eles pertencem os textos que podem efetivamente ser considerados "traduções" ou "transcriações interpoéticas" das obras de arte motivadoras, porque há um grau mais elevado da manifestação da função poética da linguagem nesses dois grupos textuais. (Op. cit., p.78)

Prestes chama atenção para os "vínculos paramórficos" estabelecidos entre os textos e as obras motivadoras, que seriam decorrentes da preocupação de Haroldo de Campos em articular estruturalmente a função poética junto com a metalinguística, promovendo uma crítica com invenção, essa última marcada pelas características da obra a que se refere. A presença desses vínculos permite observar os textos de Haroldo como "traduções", como Prestes fez questão de frisar. O autor é convicto em afirmar que a crítica pode ser uma tradução, dado que qualquer tradução "pressupõe necessariamente uma análise da obra a ser traduzida", e muitas vezes a escolha da obra a ser traduzida decorre de uma análise, que leva a uma tomada de atitude (crítica, portanto) por parte do tradutor. Toda a tradução criativa é "essencialmente avaliativa", dado que parte da leitura crítica, e produz um "novo original", mesmo que inspirado na obra anterior (Ibid., p. 32).

Para Prestes, em consonância com as ideias de Haroldo de Campos, a solução para o problema da impossibilidade de tradução de textos estéticos encontrase no conceito de "isomorfia", oriundo da Química, que representa uma "semelhança operativa", algo "mutuamente referencial" entre o original e a tradução. Apesar de ser elaborado em outro sistema artístico, o texto recriado é um "produto estético isomórfico" ao "texto motivador", pois são semelhantes na maneira peculiar com que os artistas utilizam esses códigos para a criação das mensagens estéticas (1997, p.33-34). Prestes dedica parte de sua dissertação à análise dos textos de Haroldo e das obras visuais que os 
motivaram, identificando paralelos nas estruturas dos dois, a partir da leitura atenta de um e de outro.

Segundo Prestes, seu trabalho ocupa-se de "levantar as relações paramórficas entre obras motivadoras e textos motivados" nessa produção de Haroldo de Campos, que ele definiu como uma mescla de transcriações e traduções intersemióticas: "transcriações interpoéticas". Nelas, fica realçado o "diálogo do signo interpretado com o repertório do intérprete", expandindo o espaço da interpretação na tradução, uma vez que o que está em questão é a função poética dos signos. Prestes chama atenção para o fato de que o resultado da tradução de uma obra de arte deve ser necessariamente outra obra de arte, um signo novo e autônomo. Seu procedimento metodológico reside predominantemente na análise comparativa das formas envolvidas, buscando nelas fatores de identificação (Ibid., p. 212).

Entre os desenhos de Mira Schendel e o poema de Haroldo de Campos referente a eles, por exemplo, Prestes percebe uma tentativa do poeta de repetir os fatores de síntese e redundância que caracterizam a obra visual. Para isso, elabora um texto enxuto e sem pontuação, com destaque para as aliterações (que são redundâncias), além da forma do poema (verso livre), que, de certo modo, imita a liberdade dos desenhos. Já no texto para a série Anamorfas, de Regina Silveira, Prestes destaca que Haroldo de Campos faz uso de palavras-montagens (ao modo de James Joyce), que entram em sintonia com a ambiguidade das imagens. Para ele (Ibid., p.109), o poema recria as imagens das obras visuais através de associações dos substantivos que designam os objetos visuais representados com prefixos, adjetivos e outros substantivos, na tentativa de reconstruir as deformações pelas quais as imagens passam nas obras da artista. No Polipoema para Mary Vieira, Haroldo de Campos busca reinventar o prazer lúdico proporcionado pela escultura Polivolume Disco Plástico e adota procedimentos similares com a obra de outros artistas. ${ }^{5}$

\footnotetext{
${ }^{5} \mathrm{Um}$ caso particularmente interessante entre os estudados na dissertação é $A$ Criação do Mundo \& o Tempo, poema elaborado a partir da série homônima do pintor José Roberto Aguilar, a qual, por sua vez, era uma transcriação da versão de Haroldo de Campos (outra
} 
Passaremos em seguida às formulações teóricas de Aguinaldo Gonçalves, a começar pelo livro Transição e Permanência, onde o autor analisa as relações entre a obra do poeta João Cabral de Melo Neto e o legado do pintor Joan Miró. Para Gonçalves (Op. cit., p. 24), ocorre na poesia de João Cabral um tipo especial de figurativização na qual se constrói uma identidade formal entre o "sistema verbal" usado pelo poeta e o "sistema plástico" do pintor. A predileção de Cabral pelas artes plásticas é sabida, e mesmo a influência dessas sobre a sua produção. Analisando as estruturas fundamentais do livro de poemas $A$ Educação pela Pedra sob a perspectiva da "poesia do olho", aquela que só é possível se perceber através da "dimensão integradora do signo verbal à sua potencialidade icônica", Gonçalves percebe que elas constituem, com as obras de Miró, "homologias estruturais" (p. 25). O autor expressa o conceito da seguinte forma:

\begin{abstract}
Mais que uma busca de correspondências entre os elementos mínimos constitutivos de cada uma das duas artes (cor-som, linha-sintaxe, etc.), acredito num princípio consciente de construção, em que esses elementos são utilizados como ingredientes, mas em relação aos demais, próprios de cada sistema. São procedimentos construtivos que podem ser aprendidos por um e outro artista, da arte vizinha, e são eles responsáveis pela homologia estrutural entre as artes. (Op. cit., p. 168)
\end{abstract}

Segundo Gonçalves, o texto de Cabral possui um tipo de linguagem cujo "plano de expressão se manifesta homólogo ao plano de expressão da linguagem da pintura" em Miró. $O$ autor observa que a questão da homologia estrutural entre as artes, sobretudo entre poesia e pintura, acentuou-se bastante no século XX, independente da intenção dos artistas buscarem ou não suas bases criativas explicitamente nos procedimentos de outro. Mas o diferencial do caso estudado é que Cabral conhecia bem os procedimentos criativos de Miró, de modo que,

transcriação poética) da parte inicial do livro de Gênesis, intitulada A Cena da Origem. Temos, portanto, uma sequência de três transcriações a partir do trecho bíblico, que buscam "suscitar qualidades e sentimentos semelhantes" ao original, revestindo-o sempre de uma nova forma. Prestes afirma que as obras compõem, a partir de seus resultados em diferentes matérias, pictórica e poética, uma "sinergia dialógica" (1997, p. 207-211). 
entre as diversas influências que marcaram seu trabalho, esta teve uma função fundamental (1989, p. 26).

Gonçalves denomina "intersemioticidade" o fato de certos modelos estruturais criados pelo pintor ocorrerem de modo homólogo na obra de Cabral. A influência de um sistema em outro amplia os campos de possibilidade de realização em cada meio através do estabelecimento de intercâmbios entre os códigos e os procedimentos que lhes são próprios. Gonçalves lembra a citação de Vassily Kandinsky: "uma arte pode aprender da outra o modo com que se serve de seus meios para depois, por sua vez, utilizar os seus da mesma forma; isto é, segundo o princípio que Ihe seja próprio exclusivamente" (Ibid., p. 27). A seu ver, ela ilustra bem os procedimentos adotados por João Cabral:

Observando algumas gravuras de Miró, pude perceber que o mesmo processo de composição era utilizado por ele em trabalhos cuja macroestrutura se mantinha praticamente a mesma, enquanto os elementos figurativos acrescentados e alterados nem sempre se evidenciavam aos olhos do observador. Em Cabral, essa técnica revela o ponto alto das relações intertextuais, pois as composições emparelhadas apresentam vários tipos de nuanças no esquema de alteração, criando, às vezes, uma aparente identidade entre os textos. (Op. cit., p. 121)

A aliança entre um profundo racionalismo criador e uma sensibilidade não menos profunda são características que Gonçalves aponta como comuns em Cabral e Miró, bem como a busca de rupturas constantes com a lírica tradicional (Cabral) e com a pintura clássica (Miró). Ambos também revelam a busca de um dinamismo, em dois sentidos: a superação dos seus próprios mecanismos de composição, e o tipo de mobilização que suas obras conseguem provocar na consciência do fruidor (Ibid., p. 129). Algumas das obras dos dois autores analisadas por Gonçalves também se assemelham pelo fato de serem recriações de outras obras, como no caso da pintura Interior Holandês, recriação do quadro O Tocador de Alaúde (Séc. XVII), e o poema Quaderna, de Cabral, inspirado em Carta aos Puros, de Vinícius de Morais. As duas versões, segundo Gonçalves, subvertem as criações originais, 
desvinculando-as das regras tradicionais e da conceituação clássica de beleza (Ibid., p.148).

Suas reflexões apontam para a compreensão da arte como um fenômeno cuja unidade é dada pela "supremacia da orientação estética", independente da variedade de materiais utilizados e da diversidade dos objetivos dos diversos ramos da criação artística. O fato de a poesia, por exemplo, se valer da linguagem dos signos "simbólicos", e a pintura da dos signos "icônicos", determina "lutas distintas em busca de um mesmo alvo" (Ibid., p. 173). Para o autor, existe na obra de arte um componente mobilizador das nossas condições existenciais que determina a sua natureza, independente de se manifestar como um símbolo poético ou uma imagem visual. Gonçalves lembra que, no processo criativo, ou no "profundo processo de depuração do signo", a arte "arrasta resíduos do mundo e com isso arrasta resíduos da vida pessoal" (p. 174), e cita Malraux, para quem "a obra de arte não é criada a partir da visão do artista, mas a partir de outras obras" (p. 24).

Posteriormente, em Laokoon Revisitado, Aguinaldo Gonçalves deu continuidade a esse raciocínio. Nesse livro, as relações entre o Livro II da Eneida de Virgílio (Séc. I a. C.), onde o poeta conta o castigo sofrido por Laokoon, e a escultura em mármore Laocoonte, de Alexandre de Rodes (50 a. C.), dão margem a uma nova série de interpretações. A questão da homologia estrutural é a meta principal do trabalho, tendo-se aí mais uma vez a homologia entre pintura e poesia, entre o "sistema plástico-pictórico" e o "sistema poético". Para o autor, tais relações ocorrem, sobretudo, em obras que, além de se valerem de seus próprios meios, ampliam suas possibilidades expressivas, recorrendo a procedimentos de outras artes, sem gerar concorrência entre os gêneros, mas "mútuas iluminações" (Op. cit., p. 18).

Segundo Gonçalves, o estudo crítico das analogias entre pintura e poesia remonta à Antiguidade; foi retomado a partir do Renascimento e intensificou-se no século $X X$. Entretanto, foi perturbado por visões tendenciosas que privilegiavam ora o texto, ora a imagem, e costumavam forjar correspondências, elevando-as ao nível de identificação. A necessidade de 
definição da arte, acentuada nas atividades filosóficas do séc. XVIII (em Emmanuel Kant, por exemplo), somada à necessidade de sua valorização frente às Ciências Humanas, foram fatores que impulsionaram os estudos comparativos, que normalmente buscam traçar paralelos entre as artes temporais (poesia e literatura) e as artes visuais (Ibid., p. 19-29).

Para pensar de modo mais adequado as questões que implicam o uso de recursos de um sistema de signos para outro, Gonçalves recorre mais uma vez a Kandinsky:

A comparação entre os meios próprios de cada arte e a inspiração de uma arte em outra, só é válida se não for externa, mas de princípio. Quer dizer, uma arte pode aprender com outra o modo com que se serve de seus meios para depois, por sua vez, utilizar os seus da mesma forma; isto é, segundo o princípio que lhe seja próprio exclusivamente. Nessa aprendizagem, o artista não deve olvidar que cada meio tem uma utilização idônea e que a questão é tratar de encontrá-la. (Op. cit., p. 208)

Os procedimentos construtivos de uma arte podem ser capturados por outro artista, da arte vizinha, constituindo a homologia estrutural entre as artes. Esta contém analogias entre os sistemas artísticos envolvidos, perceptíveis a partir de uma análise de suas estruturas através da qual poderemos perceber as correspondências "fisiológicas" entre as duas artes (1994, p. 225). Exemplo disso é a análise que Gonçalves faz das correspondências entre o poema Soidão, de Oswald de Andrade, e a pintura A Árvore Vermelha, de Mondrian (p. 232-246). Nela o autor detecta um princípio construtivista similar que os aproxima: "o poema enquanto processo de reconstrução ou de recuperação polissêmica do arcaísmo, e o quadro, baseado num processo de desrealização icônica". Para ele, a relação entre essas obras permite falar de uma "linguagem total", que constitui uma unidade "não-explícita, mas latente, "que deve ser perseguida" nas análises.

Outro autor cujas obras podem contribuir em nossa busca por percursos possíveis para o estudo da tradução de poesia através de diferentes meios é 
Claus Clüver, que publicou On Intersemiotic Transposition, texto com reflexões iniciais sobre a "transposição intersemiótica". Elas remetem a um conto no qual um candidato à Academia Imperial de Pintura Chinesa no século VIII pintou, a partir do verso "Deep mountains, somewhere a bell", a figura de um macaco com uma mão no ouvido, parado diante de algumas montanhas. Tanto um leitor oriental quanto um ocidental, segundo Clüver, em suas diferentes perspectivas de leitura, perceberiam uma "equivalência de essência" entre os dois. Independente de ser considerado ou não uma tradução, fato que iria variar de acordo com os valores críticos de quem lê, a figura evoca uma realidade que não é diretamente "representada" pelas palavras, mas sim "ligada" a elas.

Segundo Clüver (Op. cit., p. 56), alguns críticos poderiam comentar que, para ser considerada uma tradução, a figura deveria servir como uma substituição self-contained do original. Ao invés disso, essa figura, se separada do texto verbal, permite uma grande variedade de interpretações, algumas delas completamente diferentes daquilo que o verso do poema quer dizer, o que, definitivamente, o descaracterizaria como uma tradução. No entanto, não deixaria de ser uma pintura do verso original. Ao compará-lo com a tradução inglesa de um poema espanhol, por exemplo, Clüver observa que o leitor não estaria abordando-o da mesma maneira que abordaria se soubesse que se trata de um texto original. Mas o poema original seria normalmente substituído por sua tradução, enquanto o verso chinês não foi substituído pela pintura. $O$ autor considera que, se aceitamos a ideia de que um poema inglês pode ser recriado como um poema espanhol, deveríamos também aceitar que uma pintura pode ser traduzida em um poema. Para Clüver, encontrar equivalentes em um sistema semiótico diferente pode ser mais difícil, e os sacrifícios podem ser maiores, mas uma "transposição intersemiótica" bem sucedida não é menos possível do que uma tradução interlingual bem sucedida de um poema (p. 61).

Segundo o autor alemão, o tradutor de um poema decide quais aspectos formais são indispensáveis em sua recriação, baseado nos hábitos interpretativos de sua audiência. Ele pode, por exemplo, sacrificar a 
significação de um verso em detrimento da preservação do ritmo ou da sonoridade. Do mesmo modo, no caso de uma transposição intersemiótica, as intenções de quem transpõe definem a importância e o sentido do que será transposto. Um poema pode estabelecer diferentes relações com a obra na qual se baseia: pode ser uma interpretação, uma meditação, um comentário, uma crítica, uma imitação, uma contracriação ou outras coisas, mas todos evocarão uma imagem mental da obra original, derivada dos vestígios dela que descobrimos na tradução (Ibid., p. 61-69).

Analisando as distorções que ocorrem em relação ao original numa transposição intersemiótica, o autor lembra que elas podem tratar-se de um ato calculado para obter um efeito especial (1989, p. 70). Observa também o modo como o conceito de "transcriação" é trabalhado por Haroldo de Campos, no qual, segundo ele, liberdades que seriam questionáveis em traduções "convencionais" são frequentemente tomadas, às vezes sacrificando a fidelidade semântica em função de uma melhor equivalência formal e estilística. No entanto, essas iniciativas ainda são compreendidas como "traduções", no sentido mais flexível atribuído por Roman Jakobson ${ }^{6}$, para quem a estratégia adotada pelo tradutor depende da função que o novo texto pretende desempenhar. Essa função pode justificar a estrondosa presença da voz do tradutor, com suas distorções e omissões (p. 75-76).

Apesar de Clüver considerar os signos verbais inadequados para traduzir dados visuais (dada a violência sofrida pelo texto visual nesse processo), o autor ressalta que as transposições intersemióticas trabalham com signos que permitem a construção de um significado muito similar ao significado construtível do signo original em outro sistema de signos. Mas é importante ter sempre em mente que os significados são conferidos pelos leitores de acordo com códigos, convenções e normas interpretativas mantidas por suas comunidades. Às vezes, é preferível apontar para as diversas possibilidades de

\footnotetext{
${ }^{6} \mathrm{O}$ autor observa também que, ao incluir a reformulação intralingual como categoria, Jakobson fez o conceito de tradução mais flexível do que normalmente aparece. Ele implica que a identidade de uma mensagem não deve ser considerada necessariamente dependente da identidade de formulação. A questão é em que ponto uma nova formulação tem alterado a mensagem. Essa decisão depende muito do contexto no qual a mensagem é usada, e de seus usuários.
}

Texto Digital, Florianópolis, v. 7, n. 2, jul./dez. 2011. ISSNe: 1807-9288 
interpretação, mais do que "explicitar um próprio juízo"; por outro lado, significados quase-idênticos podem ser construídos a partir de dois textos em diferentes sistemas de signos. Clüver lembra também da diversidade de atitudes que fizeram crescer o conceito de tradução, como a imitação, a adaptação, o pastiche, a paródia e, de maneira geral, toda interpenetração de obras e discursos (Ibid., p. 83-84).

No texto Interarts Studies: an Introduction percebe-se a evolução do pensamento de Clüver no que diz respeito à compreensão das relações entre diferentes sistemas de signos. Dessa vez, o foco passa para o questionamento dos limites entre os sistemas de signos das diferentes disciplinas das artes, e o que existe além, em comum a todas elas. Para o autor, a estrutura herdada das disciplinas acadêmicas, que divide as artes em escultura, pintura, dança, poesia, etc., e o tipo de tratamento por elas dado têm, há muito tempo, provado ser inapropriado para aplicar-se a muitos fenômenos culturais do cenário contemporâneo, onde os textos ${ }^{7}$ multimídia e intermídia predominam.

Segundo Clüver, o surgimento de novas tecnologias e a "explosão" das mídias no séc. $X X$ trouxeram novas formas de texto, que não cabem mais dentro da divisão das antigas disciplinas. O interesse então passou a ser focado nas dimensões que haviam sido obscurecidas pela visão tradicional. Explorandoas, ocorreu que certas classes de texto, como intermídia e multimídia, que já existiam anteriormente, acabaram sendo re-descobertas e re-avaliadas pelos pesquisadores. Formaram-se assim novos discursos transdisciplinares, envolvendo antropologia, linguística, psicologia, ciência cognitiva, semiótica, comunicação, entre outros, que trouxeram modelos para a transformação dos "estudos comparativos" entre as artes em "estudos interartes" (Op. Cit., p. 2-3).

O objeto vigente dos estudos interartes é, ainda segundo Clüver, o conjunto de relações existente entre, ao menos, dois textos, que comportam duas visões. Um estudo que trata um logo de publicidade como um poema concreto, por exemplo, discutindo-o em conjunção com outros poemas concretos, em termos

\footnotetext{
${ }^{7}$ Clüver chama de texto todo o conjunto de significantes, independente do sistema envolvido, por exemplo, texto verbal, texto visual, texto musical, etc.
}

Texto Digital, Florianópolis, v. 7, n. 2, jul./dez. 2011. ISSNe: 1807-9288 
de suas propriedades verbais e visuais, precisa entendê-lo a partir de outras visões, que não simplesmente a da persuasão. Mas Clüver fala também de conexões bem mais complexas, que acomodam diversos sistemas de signos, como o carnaval brasileiro, o cabaré, muitos tipos de song-and-dance performances, o balé, entre outros, que oferecem, por si próprios, amplo material para os estudiosos das relações interartes, sem necessitar de comparação com outras realizações. Tentar traçar uma tipologia para todos esses textos demandaria, segundo Clüver, uma quantidade imensa de diferenciações, dado os percursos nos quais as diversas mídias e os sistemas de signos envolvidos estão interconectados (Ibid., p. 7). No trecho a seguir, o autor comenta a amplitude dos estudos interartes:

O leque dos Estudos Interartes parte dos estudos de fontes, passa por questões de periodicidade, problemas de gênero e transformações temáticas, até alcançar todas as formas possíveis de imitação que ocorrem através das fronteiras entre mídias (em formas e técnicas estruturais, tendências estilísticas, e outras mais). Os Estudos Interartes abrangem, além disso, aspectos transmidiáticos como possibilidades e modalidades de representação, expressividade, narratividade, questões de tempo e espaço em representação e recepção, bem como o papel da performance e da recitação. Incluem também conceitos cunhados pela Teoria da Literatura. (2006, p. 16)

As relações estabelecidas entre as obras num processo de tradução também são um objeto dos estudos interartes, normalmente analisadas pela perspectiva da intertextualidade, da reescritura, entre outras abordagens relativas às influências que uma obra exerce sobre a outra. Para Clüver, os desenvolvimentos da teoria da tradução afetam os percursos nos quais essas relações são percebidas nos estudos interartes. Relações entendidas como "versões" de tradução ganharam destaque, mas "reescritura" acaba sendo, segundo Clüver, o conceito auxiliar para pensar essas traduções (1993, p. 10).

Segundo Clüver, enquanto a leitura de um texto que foi traduzido de uma língua verbal em outra normalmente dispensa o conhecimento do original para ser entendido, a dança e a música, por exemplo, quando baseados em uma narrativa verbal, pressupõem que a audiência a conheça. Entender um 
espetáculo de dança como uma "transcriação" de uma narrativa verbal requer, segundo o autor, processar os signos criados por corpos em movimento, normalmente junto com signos musicais, e relacionar isso com uma versão que lembra aquela narrativa (1993, p. 10). O autor alemão lembra também outro tipo de influência, aquela que ocorre entre grupos de textos, em duas ou mais artes, que representam um determinado gênero ou movimento, ou textos estruturados de acordo com outros, que importam suas técnicas, como os "retratos musicais", os "arabescos literários", "poemas sinfônicos", entre outros. Normalmente são casos complexos de serem analisados, pois nos processos criativos contemporâneos nem sempre se pode distinguir se o contato entre as obras é proposital ou espontâneo, fruto dos desenvolvimentos ocorridos em todas as artes (p. 11).

Traçando uma linha evolutiva, Clüver observa que, no início do séc. $X X$, a atenção era voltada para as "fontes" e "influências" nas quais os artistas se baseavam para fazer suas obras, onde encontravam suas inspirações e como essas se manifestavam num novo conjunto orgânico. Nas décadas recentes, a compreensão do texto como um conjunto mais auto-suficiente estabeleceu uma visão complexa, onde este é considerado uma atividade sócio-cultural, que dialoga simultaneamente com muitas influências. As vias pelas quais um artista recebe textos que foram criados em diferentes sistemas de signos são atualmente de extrema relevância, bem como as questões relativas à apropriação intersemiótica (Ibid., p. 14-16). Para Clüver, tornou-se corrente a ideia de que um texto é uma realização particular das possibilidades inerentes em um ou mais sistemas de signos e que a construção de seus significados atua em uma ampla área de diferentes códigos. A percepção do papel dos códigos e seu uso tem tido um particular impacto no desenvolvimento da crítica teórica e, consequentemente, também na teoria e prática dos estudos interartes. Mas a hipótese de que o significado reside no texto pelo interplay de suas estruturas internas foi substituída pela consideração do papel dos leitores e da cultura a qual pertencem. Segundo Clüver, a capacidade dos textos ditarem "os códigos a serem ativados na interpretação" é limitada, e as influências exercidas sobre os leitores dependem menos do texto em si próprio que da "comunidade interpretativa" ao qual o leitor pertence (p. 21). 
Na visão de Clüver, os únicos modelos teóricos compatíveis com grande parte dos textos artísticos contemporâneos são os amparados pela perspectiva dos estudos interartes. O autor faz questão de alertar, no entanto, que trabalhar um caso de estudo interartes não equivale a estabelecer a criação de uma nova disciplina, para igualar-se às existentes. Numa reflexão autocrítica, Clüver chega a apontar que o prefixo "inter", de estudos interartes, talvez até não seja o mais adequado para definir um modelo que desconsidera e ainda recusa as fronteiras disciplinares. Para ele, talvez "estudo transdisciplinar das artes" seja mais propício. Os rótulos, lembra Clüver, não são desimportantes, e a alteração de nomes não tem impedido o crescimento e o desenvolvimento dos estudos interartes. O autor considera que, até que haja uma estrutura institucional adequada, os estudos interartes devem ser desenvolvidos nas estruturas atualmente existentes (Ibid., p. 25).

O uso do conceito "interartes" volta a ser colocado em dúvida num artigo recente de Clüver, intitulado "Inter Textus / Inter Artes / Inter Media", onde é considerado "cada vez mais equivocado e questionável" (Op. Cit., p. 12). Nesse texto, o autor apresenta um percurso que inicia abordando a "intertextualidade" entre obras, representada pelos estudos comparativos e as buscas de analogias, passando em seguida às descrições dos estudos interartes para, finalmente, chegar à abordagem da "intermidialidade". Este último conceito é oriundo, segundo Clüver, da bibliografia alemã, e se assemelha muito aos estudos interartes ${ }^{8}$, exceto pelas particularidades significantes que o termo "mídia" possui no contexto dessa língua.

Clüver destaca que o conceito "intermidialidade" é abrangente e, aparentemente, cobre todas as formas possíveis de relação entre sistemas de signos, como as relações intertextuais entre obras, as relações entre mídias em geral (intermidiáticas), as transposições de uma mídia para outra (transposição intersemiótica) e a união (fusão) de mídias, como nos textos multimídia, intermídia e mixmídia (Ibid., p. 14-24). Abrange também todas as disciplinas

\footnotetext{
${ }^{8}$ Assim como os estudos interartes, também busca pensar as formas mistas de arte realizadas com qualquer meio de comunicação.
}

Texto Digital, Florianópolis, v. 7, n. 2, jul./dez. 2011. ISSNe: 1807-9288 
tradicionais das artes, como música, literatura, dança, artes plásticas, além de arquitetura e formas mistas, como ópera, teatro e cinema, e ainda todas as "mídias"9 e seus textos: televisão, rádio, mídias impressas, eletrônicas e digitais, etc. (p. 18). As diversas formas de combinação entre as mídias, suas transformações e transposições, enfim todas as formas de relação intermidiática são passíveis de serem analisadas através da "intermidialidade", que serve como um termo geral para definir uma abordagem dos modos específicos de relação dessa natureza (p. 31).

A análise dessas formas mistas normalmente começa, segundo Clüver, pela investigação das relações entre os elementos sígnicos e midiáticos nela contidos, independente da área de interesse maior em que são estudados (Ibid., p. 19). Clüver observa que quase todas essas formas de comunicação (mídias) receberam atenção individual da área de estudo de cada uma, isoladamente. Essas disciplinas têm consciência da sua identidade e desenvolveram seus próprios métodos de abordagem, considerando as mídias que são objetos de suas análises. Enquanto os teóricos das mídias trabalham com formas mistas e com a ação conjunta de elementos verbais, visuais, auditivos, cinéticos e performativos, os estudiosos das artes tradicionais, segundo o autor, "têm dado pouca atenção a essas formas mistas que surgem em seu âmbito e não desenvolveram quaisquer métodos adequados que Ihes fizessem justiça". Para Clüver, os estudos interartes, que atualmente são usados, sobretudo no universo dos estudos literários, devem ser compreendidos e ampliados pela visão das mídias. O autor alerta que, no futuro, provavelmente os estudos interartes passarão a ser chamados de "estudos intermidiáticos", e que ainda há muito trabalho teórico a ser feito na construção dessa área (p. 37).

As perspectivas e métodos de abordagem apresentados aqui compõem um panorama amplo e variado, do qual buscamos extrair subsídios necessários para pensar a transcriação de poesia através de diferentes mídias. As

\footnotetext{
${ }^{9}$ Cabe considerar aqui a definição de "mídia" para Werner Wolf: "um meio de comunicação convencionalmente distinto, especificado não só por canais (ou um canal) de comunicação particular(es) mas também pelo uso de um ou mais sistemas semióticos que servem para transmitir mensagens culturais" (Apud Clüver, 2006, p. 34).
} 
eventuais análises feitas com objetos desse tipo abrem espaço para revisitar questões apontadas pelos autores que vimos, estabelecendo diálogos que visem resgatar e colocar em debate as ideias, os conceitos e a terminologia apresentados aqui. Nossa expectativa foi a de ter construído um conjunto de reflexões do qual podem-se extrair conclusões sobre o melhor modo de definir e caracterizar as diferentes estratégias de transcriação adotadas na prática.

\section{Referências}

AMORIM, Lauro Maia. Tradução e adaptação: encruzilhadas da textualidade em Alice no país das maravilhas, de Lewis Carrol, e Kim, de Rudyard Kipling. São Paulo: Editora Unesp, 2005.

ANTONIO, Jorge Luiz. Poesia eletrônica: negociações com os processos digitais. Belo Horizonte: Veredas e Cenários, 2008.

CAMPOS, Haroldo de. Da transcriação: poética e semiótica da operação tradutora. Cadernos PUC, São Paulo: EDUC, 1987. p. 53-74.

CLÜVER, Claus. Inter textus, inter artes, inter media. Revista Aletria, Belo Horizonte, v. 14, UFMG, 2006.

. Interarts studies: an introduction. Swedish Version, 1993.

. On intersemiotic transposition. Poetics today, v. 10, n. 1, 1989.

GONÇALVES, Aguinaldo José. Laokoon revisitado. São Paulo: Edusp, 1994.

. Transição e permanência: Miró / João Cabral: da tela ao texto. São Paulo: Iluminuras, 1989.

JAKOBSON, Roman. Linguística e comunicação. São Paulo: Cultrix, 1971.

MACHADO, Arlindo. Arte e mídia. Rio de Janeiro: Jorge Zahar, 2007.

. Máquina e imaginário: o desafio das poéticas tecnológicas. São Paulo:

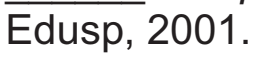

MENEZES, Philadelpho. Interpoesia: definições, indefinições, antecedentes e virtuais conseqüências. Texto integrante do CD-ROM Interpoesia. São Paulo, 1998.

PLAZA, Julio. Tradução intersemiótica. São Paulo: Perspectiva, 1987. 
; TAVARES, Mônica. Processos criativos com os meios eletrônicos: poéticas digitais. São Paulo: Hucitec, 1998.

PRESTES, Rogério Prestes de. Um poeta de vanguarda dialoga com as artes visuais: a transcriação interpoética de Haroldo de Campos. Dissertação de Mestrado, Programa de Pós-Graduação em Comunicação e Semiótica, PUCSP, 1997.

RISÉRIO, Antonio. Ensaio sobre o texto poético em contexto digital. Salvador: Fundação Casa de Jorge Amado/Copene, 1998.

SANTAELLA, Lúcia. Culturas e artes do pós-humano: da cultura das mídias à cibercultura. São Paulo: Paulus, 2004. 